\title{
O impacto da medida socioeducativa de liberdade assistida na auto-organização do projeto de vida de jovens em conflito com a lei
}

The impact of the socio-educational measure for freedom assisted in the self-organization of the youth's life project in conflict with the law

El impacto de la medida socioeducativa por la libertad asistida en la autorganización del proyecto vida juvenil en conflicto con la ley

\author{
Rafael Garcia Campos \\ ORCID: https://orcid.org/0000-0002-5836-0645 \\ Universidade Estadual Paulista, Brasil \\ E-mail: rafabael@hotmail.com \\ Dinair Ferreira Machado \\ ORCID: https://orcid.org/0000-0003-3006-7110 \\ Universidade Estadual Paulista, Brasil \\ E-mail: dinair.machado@unesp.br \\ Rubia Fernanda Quinelatto \\ ORCID: https://orcid.org/0000-0002-0827-3869 \\ Universidade Federal de São Carlos, Brasil \\ E-mail rubiafq@gmail.com \\ Willian Lazaretti da Conceição \\ ORCID: https://orcid.org/0000-0001-8143-6524 \\ Universidade Federal do Pará, Brasil \\ E-mail: lazaretti@ufpa.br
}

\begin{abstract}
Resumo
A prática de atos infracionais por jovens vem se configurando cada vez mais como questão de saúde pública, dado o impacto na vida dos/as adolescentes e da sociedade em geral. A presente pesquisa investigou o impacto da medida socioeducativa de Liberdade Assistida na auto-organização do projeto de vida de adolescentes autores/as de ato infracional. Trata-se de um estudo de natureza qualitativa, de caráter descritivo-exploratório com a colaboração de 13 adolescentes, com idade entre 12 a 18 anos incompletos. Os dados foram coletados por meio de um questionário de caracterização sociofamiliar e entrevistas individuais com roteiro semiestruturado, as quais foram gravadas e transcritas integralmente. O roteiro de entrevista contemplou questões norteadoras, as quais abordaram as experiências vivenciadas pelos/as adolescentes durante e depois do cumprimento da medida socioeducativa. Os resultados apontaram para quatro categorias significativas para auto-organização dos/as jovens na ocasião da medida: 1) Vínculos familiares e afetivos; 2) O trabalho e o estudo; 3) As relações interpessoais; 4) A relação com o/a Orientador/a. Constatou-se, nesta pesquisa, que a abordagem ampliada da medida socioeducativa conforme previsto pelo ECA e pelo SINASE impacta positivamente na auto-organização do/a adolescente e contribui para a estruturação do projeto de vida.
\end{abstract}

Palavras-chave: Projeto de vida; Conflito com a lei; Violência.

\begin{abstract}
The practice of infractions by young people is becoming more and more a public health issue, given the impact on the lives of adolescents and society in general. This research investigated the impact of the socio-educational measure of Assisted Freedom on the self-organization of the life project of adolescent authors of an infraction. This is a qualitative study, of a descriptive-exploratory nature with the collaboration of 13 adolescents, aged between 12 to 18 years old. The data were collected through a questionnaire of social and family characterization and individual interviews with semi-structured script, which were recorded and transcribed in full. The interview script covered guiding questions, which addressed the experiences of adolescents during and after the fulfillment of the socioeducational measure. The results pointed to four significant categories for young people's self-organization at the time of the measure: 1) Family and affective ties; 2) Work and study; 3) Interpersonal relationships; 4) The relationship with the Advisor. It was found, in this research, that the expanded approach of socio-educational measure as foreseen by ECA and SINASE positively impacts on the adolescent's self-organization and contributes to the structuring of the life project.
\end{abstract}

Keywords: Life project; Conflict with the law; Violence. 


\begin{abstract}
Resumen
La práctica de infracciones por parte de los jóvenes se está convirtiendo cada vez más en un problema de salud pública, dado el impacto en la vida de los adolescentes y la sociedad en general. Esta investigación investigó el impacto de la medida socioeducativa de Libertad Asistida en la autoorganización del proyecto de vida de adolescentes autores de una infracción. Se trata de un estudio cualitativo, descriptivo-exploratorio que contó con la colaboración de 13 adolescentes, con edades comprendidas entre los 12 y los 18 años. Los datos fueron recolectados a través de un cuestionario de caracterización social y familiar y entrevistas individuales con guión semiestructurado, las cuales fueron grabadas y transcritas íntegramente. El guión de la entrevista abarcó preguntas orientadoras, que abordaron las vivencias de los adolescentes durante y después del cumplimiento de la medida socioeducativa. Los resultados apuntaron a cuatro categorías significativas para la autoorganización de los jóvenes en el momento de la medición: 1) Vínculos familiares y afectivos; 2) Trabajar y estudiar; 3) Relaciones interpersonales; 4) La relación con el Asesor. En esta investigación se encontró que el enfoque ampliado de la medida socioeducativa como lo prevén ECA y SINASE impacta positivamente en la autoorganización del adolescente y contribuye a la estructuración del proyecto de vida.o resumo em espanhol.
\end{abstract}

Palabras clave: Proyecto de vida; Conflicto con la ley; Violencia.

\title{
1. Introdução
}

A violência praticada por adolescentes é um fenômeno complexo que requer diferentes estratégias de distintos setores da sociedade para o enfrentamento. Um dos desafios que se apresenta é como se deve trabalhar com adolescentes em conflito com a lei em processo de cumprimento de medida socioeducativa, garantindo seus direitos educacionais e de saúde (Maruschi et al., 2013). No caso da Liberdade Assistida (LA), foco de atenção deste estudo, ela é uma medida socioeducativa que se dá em meio aberto, sendo aplicada em atos infracionais considerados leves que não justifiquem a medida de internação (Brasil, 1990, 2012)

Do conjunto de pesquisas que elegeram a Liberdade Assistida como objeto de estudo, ainda são raros as que enfocam a percepção do/a adolescente sobre a medida socioeducativa (Costa \& Assis 2006; Brito, 2007; Passamani \& Rosa, 2009; Anjo \& Ramos, 2020). Um dos estudos que utilizou o referencial teórico-metodológico das representações sociais com adolescentes em conflito com a lei, destacou que a medida socioeducativa representa para o/a adolescente um meio que corrobora com a mudança de vida (Rosa \& Coelho, 2003).

Deste modo, a medida socioeducativa de liberdade assistida deve ser abordada sob a perspectiva da doutrina da proteção integral às crianças e adolescentes e sugere o fortalecimento da família no cuidado dos filhos a partir do debate sobre as ansiedades e angústias por quais passam os/as jovens criando dispositivos comunitários para a inserção do/a adolescente em atividades como o estudo e o trabalho (Britto, 2007). É preciso ainda, ressaltar os aspectos positivos de desenvolvimento e favorecer a emergência do potencial que todo contexto socioeducativo possui, possibilitando a construção de novas perspectivas por parte dos/as adolescentes (Costa \& Assis, 2006; Passamani \& Rosa, 2009)

Conhecer as percepções dos/as jovens é importante tanto para a construção e adequação das políticas públicas como para o desenvolvimento de práticas capazes de promover a construção de novos projetos de vida, que priorizem a educação e a saúde. Nessa linha, a Teoria da Auto-organização considera que, o ser humano é a cada momento de sua vida, o/a protagonista de sua história, na qual se torna ao mesmo tempo, produto de uma diversidade de fatores que interagem entre si, e produtor de novas formas de organização da vida, a partir das vivências a quais estão submetidos/as. Nesse sentido, ambos os momentos da existência humana são classificados por essa teoria ora como produto e produtor, utilizando assim respectivamente os termos "hétero-organização pessoal” para quando a pessoa é determinada por fatores internos e externos, previamente estabelecidos e "auto-organização pessoal" para quando a pessoa recombina tais heranças em novos padrões de existência, a partir da formulação implícita ou explícita de projetos de vida (Pereira Jr.; Pereira, 2010, p. 102).

Diante deste contexto, o presente artigo analisa o impacto da medida socioeducativa de liberdade assistida na autoorganização do projeto de vida de adolescentes em conflito com a lei. 


\section{Metodologia}

Trata-se de um estudo de natureza qualitativa, de caráter descritivo-exploratório, que buscou entender a complexidade dos fenômenos envolvidos nas relações sociais e culturais de adolescentes em conflito com a lei, que estavam em cumprimento de medida socioeducativa de liberdade assistida. Essa modalidade de estudo analisou a interação entre o ambiente e as pessoas, sendo que estes devem ser abordados em sua forma holística e não reduzidos a variáveis (Minayo, 2004).

Considerando o escopo da pesquisa, os procedimentos éticos adotados foram a submissão do Projeto de Pesquisa ao Comitê de Ética e Pesquisa em Seres Humanos, com aprovação segundo nota técnica e número de parecer 2.048 .748 e visando assegurar o anonimato foram utilizadas as iniciais dos nomes para referenciar os/as colaboradores/as, restringindo a identificação.

Participaram da pesquisa 13 adolescentes com idade entre 12 e 18 anos incompletos. Os critérios de inclusão foram adolescentes em cumprimento da medida de liberdade assistida que concordaram em participar da pesquisa e que estivessem na fase final do processo, conforme a avaliação do orientador social. A fase de extinção da medida socioeducativa de liberdade assistida (LA), é compreendida como conclusiva da medida socioeducativa, é o período em que o/a jovem adolescente está em avaliação, aguardando o posicionamento do judiciário para aprovação e arquivamento do processo.

Os dados foram coletados utilizando como técnica o questionário de caracterização sociofamiliar e, posteriormente, com entrevistas individuais com roteiro semiestruturado, as quais foram gravadas utilizando equipamento de gravador de áudio e a seguir foram transcritas integralmente. $\mathrm{O}$ roteiro de entrevista contemplou aspectos que abordaram as experiências vivenciadas pelos/as adolescentes durante e depois do cumprimento da medida socioeducativa, tais como: fale sobre o atual momento de sua vida; Como você se vê daqui a 05 e 10 anos? Como você era antes de cumprira medida (seus planos de vida, sua relação com as pessoas); como a medida impacta seu jeito de pensar? Quais cursos e oficinas participou durante a medida; Como você relaciona o aprendizado do Programa com seu dia a dia? Quais os planos para o futuro?

As entrevistas foram agendadas antecipadamente, com responsável legal do/a adolescente e com o/a jovem em cumprimento da medida. Para a realização da entrevista, foi disponibilizado o espaço de atendimento na instituição em que o/a adolescente é atendido/a, em uma sala reservada. Nesse espaço, o pesquisador recebe o/a adolescente e seu responsável legal. Para análise dos dados foi utilizada a análise de conteúdo de Bardin (2011) conceituada como um conjunto de técnicas para análise de comunicações de: expressão, de relações, temática e a análise da enunciação.

\section{Resultados e Discussão}

O contexto social e econômico dos/as adolescentes entrevistados/as compôs as categorias investigadas: escolaridade, trabalho; renda familiar per capita, composição familiar e reincidência na autoria do ato infracional. Os/as colaboradores/as de pesquisa pertenciam doze ao sexo masculino e um ao sexo feminino, com idade média de 16 anos conforme é possível verificar no Quadro 1 - Caracterização dos/as adolescentes em cumprimento de medida socioeducativa em liberdade assistida (LA) (Campos, 2017). 
Research, Society and Development, v. 10, n. 5, e9910514792, 2021

(CC BY 4.0) | ISSN 2525-3409 | DOI: http://dx.doi.org/10.33448/rsd-v10i5.14792

Quadro 1 - Caracterização dos/as adolescentes em cumprimento de medida socioeducativa em liberdade assistida (LA).

\begin{tabular}{|c|c|c|c|c|c|c|}
\hline Adolescente & Sexo & Idade & Escolaridade & Ocupação & Ato Infracional & $\begin{array}{c}\text { Múltiplas } \\
\text { passagens }\end{array}$ \\
\hline $\mathrm{J}$. & Masculino & 17 & Ensino Médio (incompleto) & Cuidador & Tráfico de entorpecentes & 2 \\
\hline D. & Masculino & 17 & Ensino Fundamental (incompleto) & - & Tráfico de entorpecentes & 0 \\
\hline C. & Feminino & 15 & Ensino Fundamental (cursando) & Estudante & Furto de chocolate & 0 \\
\hline G. & Masculino & 16 & Ensino Fundamental (cursando) & Servente & Compra de celular roubado & 0 \\
\hline \multirow{2}{*}{$\mathrm{O}$. } & \multirow{2}{*}{ Masculino } & \multirow{2}{*}{17} & \multirow{2}{*}{ Ensino Fundamental (incompleto) } & \multirow{2}{*}{-} & Tráfico de entorpecentes & 1 \\
\hline & & & & & Compra de moto roubada & 1 \\
\hline V. & Masculino & 17 & Ensino Médio (cursando) & Servente & Tráfico de entorpecentes & 0 \\
\hline D. & Masculino & 15 & Ensino Médio (cursando) & Estudante & Atirar fogo no chão da escola & 0 \\
\hline C. & Masculino & 16 & Ensino Fundamental (cursando) & Estudante & Furto de chocolate & 0 \\
\hline $\mathrm{L}$. & Masculino & 16 & Ensino Fundamental (cursando) & Estudante & Tráfico de entorpecentes & 0 \\
\hline \multirow{2}{*}{ G. } & \multirow{2}{*}{ Masculino } & \multirow{2}{*}{17} & \multirow{2}{*}{ Ensino Médio (cursando) } & \multirow{2}{*}{ Estudante } & Tráfico de entorpecentes & 1 \\
\hline & & & & & Negligência no trânsito & 1 \\
\hline \multirow{2}{*}{ B. } & \multirow{2}{*}{ Masculino } & \multirow{2}{*}{16} & \multirow{2}{*}{ Ensino Fundamental (incompleto) } & \multirow{2}{*}{-} & Compra de bicicleta roubada & 1 \\
\hline & & & & & Tráfico de entorpecentes & 1 \\
\hline M. & Masculino & 17 & Ensino Fundamental (incompleto) & $\begin{array}{l}\text { Ajudante } \\
\text { Jardineiro }\end{array}$ & Tráfico de entorpecentes & 0 \\
\hline $\mathrm{N}$. & Masculino & 17 & Ensino Médio (cursando) & Servente & Furto & 0 \\
\hline
\end{tabular}

Fonte: Campos (2017). 
No Brasil, de acordo com o relatório divulgado pelo Sistema Nacional de Atendimento Socioeducativo ao Adolescente (Brasil, 2017) publicado em 2017 havia cerca de 18.000 adolescentes privados de liberdade em regime de cumprimento de medida socioeducativa de internação em instituição educacional (Brasil, 2017). Ao analisarmos quem são esses/as adolescentes, verificamos que $96 \%$ são do sexo masculino, a faixa etária predominante entre 16 e 17 anos de idade representando $56 \%$, e este mesmo percentual representa os adolescentes em restrição e privação de liberdade foram classificados como negros. Insta evidenciar um ponto de atenção identificado: somente 9 estados registram dados relativos aos adolescentes LGBTQI+, o que remete a negligência do conhecimento e respeito às especificidades desta população. A pesquisa fora realizada em um Centro de Internação no Estado de São Paulo, o qual detinha cerca de 7.000 mil adolescentes em privação de liberdade no período mencionado.

Constatou-se que 09/13 adolescentes frequentavam a escola, cinco estava cursando o ensino fundamental II na ocasião da pesquisa, quatro cursava o ensino médio e quatro havia interrompido os estudos por aguardar vaga para o período noturno, negativa de matrícula por parte da escola, aguardar vaga para o supletivo e porque a família considerava um risco para a reincidência do conflito com a lei seu retorno ao âmbito escolar.

Ao analisar a exclusão na escola, Dubet (2003) distinguiu-se em exclusão da escola e exclusão na escola. Segundo o autor, a exclusão da escola contempla tanto o não acesso como a evasão escolar, enquanto a exclusão na escola representa a exclusão produzida no processo escolar, por meio da reprovação do/a aluno. Entender o papel da escola no processo de exclusão escolar implica compreender os mecanismos pelos quais ela, por sua própria ação, acrescenta fatores de desigualdades e exclusão que ultrapassam a simples reprodução das desigualdades sociais. Algumas das situações geradas na e pela escola impactam inclusive, na preferência de docentes em lecionar em contextos socioeducativos como é possível verificarmos nas pesquisas de Conceição (2017, 2020) e Müller et al. (2021).

Quinelatto (2015) analisa o exposto da seguinte forma:

Tal violência e exclusão social, por sua vez negligenciam ao outro o direito ao reconhecimento e à identidade social. São modos característicos de comportamentos normativos vigentes da vida cotidiana que não observa ou considera a existência do outro, atua de forma intersubjetiva e torna-se concreto em práticas do senso comum, nos diversos espaços sociais. Neste contexto, a prática do ato infracional, por sua vez, carrega em si determinados estigmas, que marcam a vida do autor, bem como podem dificultar a participação do mesmo na sociedade tida burguesa. Os estigmas são como rótulos, que definem algo e/ou alguém a partir de um fato relevante e não considera o ser humano amplamente, que pode ter passagem pelo Programa de Medidas Socioeducativas e, ao mesmo tempo, ser um aluno de destaque na escola (p.76).

Em relação ao trabalho, durante a pesquisa de campo, quatro adolescentes realizam atividade remunerada, sendo que dois deles também estudam e trabalham e dois apenas trabalham.

Segundo Barbieri (2019), o Brasil, terceiro maior país nas taxas de aprisionamento do mundo, atrás apenas dos Estados Unidos e da China, conta hoje com 812.564 adultos em cumprimento de regime fechado e semiaberto. Os números revelam um aumento significativo, se comparados às taxas de 2016, quando o total de presos era de 726 mil, de acordo com o Levantamento Nacional de Informações Penitenciárias do Departamento Penitenciário Nacional (DEPEN), do Ministério da Justiça. Vale pontuar que, atualmente, $70 \%$ das prisões estão com um número de presos maior que a capacidade, o que significa um déficit de quase 300 mil vagas no país. O descaso no processo de escolarização se perpetua no sistema prisional, dadas as precárias condições em que a população cumpre pena, onde apenas 10,5\% participam de atividades educativas e $18,54 \%$ realizam algum trabalho.

Quanto ao ato infracional, 08/13 dos/as adolescentes estavam cumprindo a medida por tráfico de entorpecentes, 03 por furto, sendo dois furtos de chocolate, e um por ter adquirido produto roubado. Esses dados, apesar de não serem expressivos em termos quantitativos, contrapõem o senso comum de que são adolescentes violentos e que predomina o 
latrocínio como ato delitivo.

Silva e Salles (2011), relatam que os/as adolescentes entrevistados por eles, ao se referirem do ato infracional que cometeram, explicam sua motivação pelo dinheiro que puderam obter por meio do tráfico de drogas, além da facilidade de ingresso, já que residem em locais onde o tráfico é potencializado; pelo uso de drogas; pela influência de amigos/as; por relações familiares turbulentas e pela restrição de trabalho na adolescência.

No Quadro 2 - Caracterização familiar dos/as adolescentes em cumprimento de medida socioeducativa de liberdade assistida é possível verificar as configurações dos arranjos familiares. Na análise, 5/13, tinham a família chefiada pelo pai, 3/13 tinham como provedor familiar a mãe, 4/13 as avós, 1/13 o avô, 1/13 o próprio adolescente. Pelo exposto, 7/13 famílias eram providas por mulheres, mães ou avós, ou seja, a figura feminina.

Para muitas crianças e adolescentes a família é propulsora das primeiras experiências de abandono, vitimização e violência. A ideia da família como instituição, de caráter protetivo, é ressaltada como mito no século XXI. Porém, não se deve desprezar as condições concretas de vida e a falta de acesso aos direitos sociais a que estão expostas grande parte das famílias pobres, e que se deparam por problemas sociais como álcool, drogas, violência doméstica, abusos e maus tratos à população infanto-juvenil. Nesta perspectiva, faz-se necessário o investimento e a articulação de políticas sociais de atendimento e fortalecimento das famílias das classes subalternas (Teixeira, 2006).

A renda familiar per capita média das famílias dos/as adolescentes em cumprimento de medida socioeducativa em liberdade assistida foi de R \$687,93. Segundo Atlas (2020), famílias consideradas pobres e extremamente pobres, têm em média a renda per capita inferior a $\mathrm{R} \$ 255,00$ (a preços de agosto, 2020), Atlas do Desenvolvimento no Brasil (2020).

Parte dos/as adolescentes que cumprem medidas socioeducativas, contribui significativamente com a renda familiar. Por meio de "bicos" " e empregos informais, inclusive ilícitos. Constatou-se, predominantemente, as mães como arrimeis de suas famílias. Com destaque a presença de avós e de companheiras dos núcleos familiares já constituídos pelos/as adolescentes. Constatando que alguns/mas adolescentes já oriundos/as de um ciclo complexo de institucionalização e perversidade, tendo crescido em situação de rua ou frequentemente em unidades de acolhimento institucional, sem possuir vínculo familiar (Medeiros \& Paiva, 2015).

Destaca-se que 04/13 adolescentes tinham múltiplas passagens, sendo que 03/13 cumpriam a medida socioeducativa de liberdade assistida pela segunda vez e $01 / 13$ já havia cumprido a medida de internação.

Os/as adolescentes em conflito com a lei, tidos como agressores da sociedade são tratados com punição, sendo excluídos da sociedade e internados em instituições socioeducativas, tornando-se alienado/a ao sistema jurídico-político com movimento dicotômico, que segrega a categoria da infância e da juventude pobre em vítimas e infratores (Scisleski et al., 2015, p. 514).

\footnotetext{
${ }^{1}$ Bicos: Trabalho informal, podendo ser lícito ou ilícito.
} 
Research, Society and Development, v. 10, n. 5, e9910514792, 2021

(CC BY 4.0) | ISSN 2525-3409 | DOI: http://dx.doi.org/10.33448/rsd-v10i5.14792

Quadro 2 - Caracterização familiar dos/as adolescentes em cumprimento de medida socioeducativa de liberdade assistida.

\begin{tabular}{|c|c|c|c|c|c|c|c|c|c|}
\hline Adolescente & Sexo & Idade & Chefe do lar & $\begin{array}{c}N^{o} \text { moradores } \\
\text { no Lar }\end{array}$ & Renc & $\begin{array}{l}\text { niliar Per } \\
\text { ita }\end{array}$ & Casa & $\begin{array}{c}\text { Tipo de } \\
\text { localidade }\end{array}$ & $\begin{array}{c}\mathrm{N}^{\circ} \mathrm{de} \\
\text { cômodos }\end{array}$ \\
\hline J. & Masculino & 17 & Pai & 7 & $\mathrm{R} \$$ & $1.287,14$ & Alugada & Urbana & 5 \\
\hline D. & Masculino & 17 & Pai & 5 & $\mathrm{R} \$$ & 616,00 & Alugada & Urbana & 5 \\
\hline C. & Feminino & 15 & Mãe & 6 & $\mathrm{R} \$$ & $1.183,33$ & Financiada & Urbana & 4 \\
\hline G. & Masculino & 16 & Pai & 4 & $\mathrm{R} \$$ & $1.000,00$ & Própria & Urbana & 4 \\
\hline O. & Masculino & 17 & Avô & 5 & $\mathrm{R} \$$ & 640,00 & Própria & Urbana & 6 \\
\hline V. & Masculino & 17 & Adolescente & 2 & $\mathrm{R} \$$ & 250,00 & Cedida & Urbana & 3 \\
\hline D. & Masculino & 15 & Pai & 4 & $\mathrm{R} \$$ & 750,00 & Financiada & Urbana & 4 \\
\hline C. & Masculino & 16 & Avó & 6 & $\mathrm{R} \$$ & 197,33 & Cedida & Urbana & 4 \\
\hline L. & Masculino & 16 & Mãe & 2 & $\mathrm{R} \$$ & 425,00 & Própria & Urbana & 4 \\
\hline G. & Masculino & 17 & Avó & 4 & $\mathrm{R} \$$ & 845,00 & Própria & Urbana & 8 \\
\hline B. & Masculino & 16 & Avó & 5 & $\mathrm{R} \$$ & 456,00 & Própria & Urbana & 11 \\
\hline M. & Masculino & 17 & Mãe & 3 & $\mathrm{R} \$$ & 626,67 & Própria & Urbana & 4 \\
\hline $\mathrm{N}$. & Masculino & 17 & Pai & 6 & $\mathrm{R} \$$ & 666,67 & Alugada & Urbana & 4 \\
\hline
\end{tabular}

Fonte: Campos (2017). 
Após análise das entrevistas foi possível identificar quatro categorias que apontam como a medida socioeducativa impacta na auto-organização de projetos de vida, sendo elas: 1) Vínculos familiares e afetivos; 2) O trabalho e o estudo; 3) As relações interpessoais; 4) A relação com o/a Orientador/a.

\section{Vínculos familiares e afetivos}

De acordo com Pereira Jr., Lussi e Pereira (2002), a categoria família representa na vida das pessoas existência e referência para construção afetiva do eu. A família é incumbida pelo estabelecimento dos primeiros vínculos, e é na família que os indivíduos vivenciam a representação de papéis.

Para o adolescente (V, 17 anos) não houve vínculo afetivo com a mãe por conta das constantes brigas com o padrasto “Já morei já... cheguei a morar uns anos com minha mãe, mas, ela brigava muito com o meu padrasto e eu acabava tretando ${ }^{2}$ com ele, sai de casa e fiquei morando com minha vó" A dinâmica e os vínculos familiares influenciam na formação da personalidade e no desenvolvimento biopsicossocial do indivíduo.

Observou-se que mesmo com sentimento positivo em relação ao pai, o adolescente (V, 17 anos) relata situação de violência por parte dele "Meu pai era carinhoso, mas, minha mãe disse que ele tentou me matar uma vez, eu não lembro, era muito pequeno. Ele era doidão, cheirava cola". Embora o adolescente reconheça o comportamento inadequado do pai e não tenha convivido por muito tempo com ele, fala sobre ele com certo orgulho, "Não cheguei a conhecer ele. Ouvi boato que ele era foda hein! Dava trabalho. Ele morreu eu tinha uns cinco anos, levou um tiro, foi assassinado" (V., 17 anos).

O mesmo fato se ocorreu com os/as adolescentes (G., 17 anos), (O., 17 anos), (V., 17 anos) e (C.; 15 anos) que foram criados/as pelas avós desde tenra idade, não conheceram os pais biológicos, devido à morte ou prisão deles e em algum momento da vida ou foram abandonados por suas mães ou decidiram não morar com elas devido aos conflitos com seus padrastos. “Ah, meu pai não tem muito o que falar, ele está preso por tráfico de drogas". (C, 15 anos).

Ambos experimentaram o sofrimento diante do rompimento com os vínculos familiares e hoje reconhecem as avós por terem assumido esse papel. O adolescente G., 17 anos, mora com sua avó desde o suicídio de sua mãe e por seu pai estar detido.

É expressiva a angústia que o desconhecimento do pai e o distanciamento da mãe, causa no adolescente (C., 16 anos), ao falar que ele e os três irmãos mais novos, moram com a avó desde que nasceram por motivo de não conhecer seu pai e a mãe ser usuária de entorpecente e ter perdido a guarda dele e dos três irmãos para os avós. "Só conheço minha mãe, meu pai eu nunca vi (pausa) minha mãe de vez em quando vai lá em casa, minha avó tem a nossa guarda". Questionado se ele já tentou aproximação da mãe, relata que sim e que houve diversas tentativas de buscar ajuda para interná-la e em nenhuma tiveram sucesso.

Por outro lado, o adolescente (B., 16 anos), mora com a avó desde que nasceu, mas relata ter bom relacionamento com a mãe. Afirma que não se acostumou a morar com ela, porém mantém proximidade e vínculo fortalecido. O adolescente também não conheceu e não sabe o paradeiro do pai biológico. A mãe e os avós, muitas vezes, cumprem o papel do pai, este que se faz ausente por diversos motivos na vida de seus filhos.

\section{O trabalho e o estudo}

O trabalho parece significar para os/as adolescentes atividades que apoiam transformações, implicando em equilíbrio e autonomia, que podem gerar acesso à educação e a saúde. O/a adolescente em conflito com a lei, que tenha adquirido

\footnotetext{
${ }^{2}$ Brigando.
} 
experiência do trabalho legalizado, pode ressignificar o ato infracional, criando possibilidade da construção de um projeto de vida (Jacobina \& Costa, 2007).

Ao longo do processo de socialização, o trabalho tornou-se importante referencial para o desenvolvimento emocional, ético e cognitivo do indivíduo. Se transformando em uma base social consolidada, na atividade principal e no elemento definidor, ainda que não exclusivo, como sentido da vida. Em razão disso, a falta do trabalho assume, igualmente, um papel essencial.

O adolescente (J., 17 anos), comenta que parou com os estudos no terceiro ano do ensino médio "Meu pai não quis me matricular ainda lá na escola que é pra pegar um pouco mais de confiança em mim... Hoje eu sou cuidador... eu entro sete horas... aí eu vou embora três horas...Agora eu gosto... antes eu não gostava não do trabalho... mas agora eu gosto... agora eu trato eles como se fosse da família, né...".

Assim acontece, com G., 16 anos, que também trabalha com o pai como servente e estuda no período noturno. Almeja ser como seu avô paterno que foi um exemplo para ele, trabalhou bastante, conseguiu juntar dinheiro e deixar para seus filhos, como explica, e especificamente para seu pai, uma profissão.

Trabalhar significa viver, sair do discurso e praticar seus saberes e habilidades, construir identidade social para se confrontar o mundo. O trabalho corrobora para construção de uma representação de si mesmo, auxilia a ressignificação das relações familiares e sociais, principalmente dos/as adolescentes em conflito com a lei. A pessoa que trabalha é munida de responsabilidades, deve planejar, organizar e executar as atividades de maneira crítica e criativa, para obtenção de melhores resultados em seu trabalho (Jacobina \& Costa, 2007).

O curso de injeção eletrônica, oferecido pelo Centro Regional de Registro e Atenção aos Maus Tratos Na Infância CRAMI, despertou no adolescente (C., 16 anos), o desejo de trabalhar e seguir uma profissão. Por meio dos incentivos recebidos nas aulas do curso de formação profissional, conseguiu fazer uma projeção futura. "Eu me vejo trabalhando daqui cinco anos... com o que eu quero aprender... que é mecânica... quero aprender mecânica quântica... quero chegar nesse nível...mas... daqui cinco anos eu me vejo querendo estudar mecânica memo... ser um mecânico formado".

É evidente que muitos/as adolescentes são convidados/as e aceitam traficar entorpecentes, devido ao retorno financeiro que esta atividade ilícita e criminosa proporciona. Conforme explicado pelo adolescente (G., 17 anos). "Eu gosto de trabalhar com mecânica (pausa) mas eu memo... trabalhava o mês inteiro pra ganhar setecentos real... aí fui vender no corre não dava dois dia eu já tinha setecentos real... aí você fala nossa... olha... como que eu vou trabalhar se eu ganho isso aqui rapidinho"... aí você só vai pensando assim... vai pensando pior... aí eu comprava as coisa pra mim... roupa... tênis... boné... comprei um monte de moto...tem as roupa... tenho bastante roupa de marca... só, né...cheguei a gastar uns mil real num final de semana...".

Quinelatto (2015) mais uma vez corrobora tal entendimento de jovens autores/as de ato infracional, ao declarar que

A sociedade da forma que se organiza, pautando-se pelas necessidades burguesas não possibilita a participação, tampouco considera as necessidades, daqueles em desprestígio social. Para jovens de classe baixa, que vivem em uma sociedade racista e elitista, é fato que se tornam invisíveis aos olhos da elite. A transgressão, por sua vez, valoriza tais jovens, colocando-os em lugar de destaque social, mas não da sociedade anterior, pela coragem, bravura e esperteza, ou seja, torna-se reconhecido por outro código de valores. Nessas condições, o jovem se torna protagonista social, já que de alguma forma conseguiu trazer a atenção para si e, muitas vezes, a entrada no mundo do crime seja uma tentativa última de reforçar a identidade de provedor, forte (Quinelatto, 2015, p. 80).

As oportunidades de capacitações profissionais oferecidas pelos programas de atendimento socioeducativo, muitas vezes, é para mantê-los ocupados, ao invés de uma estratégia para ingressá-los no mercado de trabalho após o cumprimento da 
medida.

Qualquer curso, para ser implantado, critérios devem ser estabelecidos: local apropriado, definição do número de adolescentes atendidos, instrutores qualificados para atender essa população, pois o que mais nos deparamos, são pessoas despreparadas e desacreditadas da real proposta da medida socioeducativa, resultando em um trabalho não eficaz, material pedagógico e um projeto estruturado descolado da real importância para esses/as jovens (Barone \& Silva, 2015).

A inserção ao mercado de trabalho proporciona transformações em suas vidas, possibilitando autonomia, poder de compra/acesso e controle de sua própria vida. Segundo relatado nesta pesquisa, a maioria dos/as adolescentes tiveram dificuldades para retomar os estudos, devido à resistência da gestão escolar em não os/as matricular e, consequentemente, sem oportunidade de qualificação profissional e oportunidade de emprego lícito.

Desta maneira, não corroborando com o processo de empoderamento, no sentido de oportunizar a eles/as a retomarem seus projetos de vida e reescreverem uma nova história.

\section{As relações interpessoais}

O grau de desempenho dos indivíduos como sujeitos da história depende de sua autonomia e iniciativa. Logo, o indivíduo é história na medida em que se inclui e se define nas relações sociais, desempenhando atividades transformadoras nestas relações (Lane, 1997).

Fortalecer a convivência familiar, comunitária e as avaliações são fatores positivos na (re)socialização de adolescentes infratores/as, sendo fundamental ajudá-los/as a encontrar o sentido ético da vida, para então construir um novo projeto de vida, sem práticas fundadas na vigilância e na punição (Passamani \& Rosa, 2009).

Assim relata o adolescente (N., 17 anos), que sua ex-namorada ao encontrá-lo após sair de liberdade da medida socioeducativa de internação. "não... eu não quero mais ver você desse jeito e tal... tal... tal... senão não vai dar certo... você vai acabar indo preso e eu não quero ir te visitar... eи quero seu bem... aí eu fui e parei de traficar... parei de... quando eu tinha saído... parei de traficar... e tô até hoje sem traficar..."

Para o adolescente (B., 16 anos), ter amizades na escola, incentiva-o a continuar com os estudos. Igualmente ocorre com o adolescente (G., 17 anos), que percebe mudança em seu comportamento, antes e depois de cumprir a medida socioeducativa. "Depois disso foi mudando, né... por que aí você vai vendo que aquilo não compensa, né... você vai vendo uma hora que não compensa... tudo ilusão, né... dinheiro vira sim... mas se você for ver... só ilusão... por que o final é sempre o mesmo, né... só cadeia... não tem outra opção... hoje tô mais tranquilo... tô atrás de serviço... ".

De acordo com o Estatuto da Criança e do Adolescente (ECA) em seu artigo 16, a criança e o/a adolescente têm direito à liberdade e entende como direito os aspectos: liberdade de expressão, educação religiosa, brincar, praticar esportes e divertir-se, participar da vida familiar e comunitária sem discriminação, participar da vida política, na forma da lei (Brasil, 1990).

De acordo com Conceição, Teixeira e Campos (2020), entende-se que

$\mathrm{Na}$ atualidade, o presente debate é demarcado pela defesa de propostas socioeducativas que procurem integrar os direitos individuais e sociais, com práticas educativas capazes de reduzir os efeitos da privação de liberdade. A educação deve ser entendida como um processo que envolve diferentes processos educativos e relações sociais, garantindo os valores e as condições concretas estabelecidas pelos princípios constitucionais de respeito à dignidade humana (p. 10).

No entanto, falta investimento por parte do poder público na oferta de atividades educativas, recreativas e esportivas 
Research, Society and Development, v. 10, n. 5, e9910514792, 2021

(CC BY 4.0) | ISSN 2525-3409 | DOI: http://dx.doi.org/10.33448/rsd-v10i5.14792

(Oliveira et al., 2020a, 2020b, 2020c). Assim, muitos/as adolescentes deixam de brincar e abandonam os estudos para trabalhar, com objetivo de colaborar com as despesas de casa e quando não amparados pelo mercado de trabalho formal e lícito, são acolhidos pelo crime, com promessas de trabalho com rendas exorbitantes em pouco espaço de tempo.

$\mathrm{O}$ adolescente (C., 16 anos), tem como diversão passiva manter o bom relacionamento com os amigos. "Eu tenho bastante amigo... na escola eu tenho bastante amigo... ah... nos prédio eu converso com o quê... uns quatro amigo meu... um estuda na Industrial... outro estuda na mesma escola que eu... o outro não estuda mais... e tem um outro também que estuda na mesma escola que eu...”.

Pelo exposto nas narrativas e de acordo com Pereira Júnior, Lussi e Pereira (2001), a sociabilidade e o estabelecimento de laços sociais, para além do ambiente de trabalho, significa fonte de satisfação para as pessoas, uma possibilidade de ser reconhecido e sentir-se seguro no meio em que vive. O oposto também ocorre, levando-os/as ao processo de auto-desorganização, fazendo com que permaneçam na criminalidade, conforme relatado por eles/a.

\section{A relação com o/a Orientador/a}

Segundo Coelho e Rosa (2013), os/as adolescentes se consideram indignos/as de direitos e deveres e que a sociedade, de modo geral, enfrenta o ato infracional como um ato de violência e, em situações diversas, acredita que a resposta seja a aplicação da violência para combater a violência, o que é preocupante.

Torna-se essencial analisar o contexto relacional de um/a adolescente para melhor entendê-lo/a. Os principais sistemas em que o/a adolescente está inserido são constituídos por meio da família, grupo de pares e da escola. Normalmente, a criminalidade é um sistema bastante presente nos ambientes de convivência desses/as adolescentes infratores/as, e, além disso, são reflexos de uma sociedade preconceituosa (Colombarolli et al., 2014)

$\mathrm{O}$ adolescente (B., 16 anos), é reincidente e comenta que a medida socioeducativa em liberdade assistida, ajudou-lhe a refletir sobre seu ato infracional e se posicionar de uma forma diferente. "Ah... euuи... (pausa) não ligava pra nada, sabe... não tava nem aí pras consequências... Ah... eu fumava maconha na escola memo... na porta da escola... não tava nem aí... mas hoje em dia, "xééé"... não passo nem perto de maconha... (pausa) quando tem gente que fuma maconha assim... eu não tenho preconceito, sabe... mas... (pausa) perto de mim... eu já saio de perto... A medida me ajudou, né... porque agora eu tô na escola... agora eu tô fazendo curso... tô assim, né... agora tô tentando arrumar um emprego...".

É fundamental o trabalho do/a profissional que realiza o atendimento individual em que deve ser estabelecida aos/as adolescentes, condições à sua conduta, direcionando atividades planejadas, estimulando o convívio familiar, planejando sua vida escolar e profissional, foco na saúde pessoal e coletiva, bem como oportunizando elementos para (re)socialização.

Para o adolescente (B., 16 anos), as orientações dadas pela profissional que o atende têm sido importantes e têm feito diferença na forma dele lidar com as situações. "No atendimento a gente conversa se eu me dou bem com a minha mãe... eu falo que eu me dou bem com ela... ah... é tudo no papo, sabe... (pausa) só pra saber do dia-a-dia meu... (pausa) mas anda tudo normal meu dia-a-dia... tranquilo... O atendimento tem me ajudado né...Sobre a escola memo... a escola... "vish"... eu não gostava nem de passar na porta da escola...Não tinha nenhuma... aí hoje em dia estudando... terminando os estudo... Ah... ela falou que ia ser melhor pra minha vida... deu uns conselho pra mim... que ia ser melhor pra mim... que é bom terminar os estudo também... ai bateu na minha cabeça isso aí e eu resolvi terminar o estudo... fazer alguma coisa da vida, né...”.

Explica o adolescente que quando foi designado para o cumprimento da medida de liberdade assistida, no primeiro momento rejeitou, mas logo foi proposta uma oportunidade para retornar aos estudos e ele compreendeu ser uma nova oportunidade de cumprir a medida de liberdade assistida. Acrescenta que antes mesmo de voltar a cumprir a medida não 
Research, Society and Development, v. 10, n. 5, e9910514792, 2021

(CC BY 4.0) | ISSN 2525-3409 | DOI: http://dx.doi.org/10.33448/rsd-v10i5.14792

pensava parar e não se importava com as consequências de seus atos.

Reorganizar os cuidados básicos na vida, além de favorecer uma boa saúde, contribui para novos hábitos e rotinas na vida cotidiana, que auxiliam na organização da vida social (Ferreira \& Pereira, 2012).

Neste estudo, observou-se que os/as adolescentes que buscavam retomar os estudos e ingressar no mercado de trabalho não tiveram sucesso. Podendo assim, levá-los/as a uma nova fase de auto desorganização de suas vidas e reincidência na criminalidade.

Há que se ofertar espaço de reflexão, a fim de que o sujeito tenha a possibilidade de ser o/a protagonista de sua história, atuando no processo de construção de sua formação e do seu saber. A proposta é que abandonem o papel de espectadores/as e objetos da ausência de eficácia das políticas públicas, todavia um sujeito autônomo/a, engajado/a consigo e com sua família, com vistas a construir um processo civilizatório autônomo e ético (Neto \& Centolanza, 2010).

Neste contexto, Quinelatto-Caparrós (2013) promulga que o trabalho educativo realizado no e pelo Programa de Medidas Socioeducativas deve propiciar

[...] o estabelecimento de ações complementares à escola, no atendimento a jovens em situação de vulnerabilidade social, por meio da oferta de atividades culturais, esportivas, lúdicas, recreativas e formativas. Ao mesmo tempo, orienta e forma para os cuidados da saúde, na complementação à educação alimentar, na prevenção à violência doméstica e, por fim, mas não menos importante, na prevenção ao uso de substâncias químicas, lícitas e ilícitas (p. 129).

Para os adolescentes (B., 17 anos e G., 16), as orientações dadas nos atendimentos os auxiliaram em seu dia a dia, passaram a não brigar mais em meio familiar, ao retratarem que são bem recebidos pela profissional que os atendem e que sem tal apoio profissional, eles não teriam voltado a estudar e se preocupar com sua saúde.

O adolescente J., (17 anos) explica que é reincidente e já cumpriu a medida de internação na Fundação CASA e agora é assistido pela medida de liberdade assistida por outra instituição que por vezes não tem elação alguma com a Fundação CASA. Relata perceber uma mudança significativa em sua vida. "Ah... o que mais mudou em mim... foi... eи me... (pausa) eu me... responsabilizo mais, né... agora antes eu não tinha responsabilidade nenhuma... antes de eu vir assinar esse negócio aqui... agora eu tenho um compromisso de vim assinar aqui... de ter responsabilidade de estudar... fazer curso... porque é a melhora pra mim também, né...."

Assim, ressalta-se que a medida socioeducativa deve relacionar-se à educação e a saúde, com objetivo de mudança na vida desses/as adolescentes, encarada com um objetivo de resgate, responsabilizando-os/as, porém, oferecendo oportunidades como oficinas, cursos, em direção à (re)construção de seu projeto de vida (Coelho \& Rosa, 2013).

O sujeito deve ser o protagonista de sua história, participar do processo de construção de sua formação e do seu saber. Os/as adolescentes e seus/uas familiares não são simples espectadores e objetos das políticas, mas protagonistas, comprometidos/as consigo e com seus/uas companheiros/as, a fim de construir um processo civilizatório e ético (Neto \& Centolanza, 2010).

Ao realizar o atendimento com efetividade, o/a orientador/a alcançará bons resultados, como expressado pelo adolescente (J., 17 anos). “O atendimento é bom... nós conversa... ela pergunta se eu melhorei... o que que eu penso em fazer daqui dois ano... três ano... me ajuda bastante...Me ajuda a melhorar cada vez mais... deixar essas coisas pra trás e pensar no futuro meu e da minha família...”.

O mesmo aconteceu com o adolescente (M., 17 anos) ao relatar que sua vida mudou ao cumprir a medida de liberdade assistida. "Minha vida mudou... se eu não tivesse vindo pra cá... essas horas tava lá na rua ainda... fumando maconha...". 
Research, Society and Development, v. 10, n. 5, e9910514792, 2021

(CC BY 4.0) | ISSN 2525-3409 | DOI: http://dx.doi.org/10.33448/rsd-v10i5.14792

Para que a medida socioeducativa de liberdade assistida consiga ser reconhecida, respeitada pelos/as adolescentes, familiares e sociedade de um modo geral, necessita contar com a articulação do trabalho em rede social, com o poder público e participação assídua do judiciário, a fim de garantir os direitos básicos do/a adolescente assistido e toda sua família. Com o objetivo de apoiar na estruturação de sua vida escolar e profissional, proporcionando elementos para sua inserção na sociedade.

Outro aspecto importante para garantirmos melhores ações no atendimento individual dos/as adolescentes assistidos/as é valorização dos profissionais que trabalham na medida de liberdade assistida, como oferecer um plano de encarreiramento, bolsa estudo e se necessário, admissão de novos profissionais.

Além, de dispor de maiores recursos financeiros para contratação de novos cursos e atividades que possam estar condizentes com as necessidades atuais dos/as adolescentes para fortalecimento dos laços familiares, permanência na escola e ingresso no mercado de trabalho.

\section{Considerações Finais}

Neste estudo, os/as pesquisadores/as apontam que os fatores de risco que possivelmente influenciam o/a adolescente reincidir na autoria do ato infracional é o consumo de droga ilícita, demonstrando que o/a mesmo/a, fica propenso/a devido ao sustento do vício. Pela pesquisa 04/13 adolescentes reincidentes do nosso estudo relatam: B., 16 anos (consome álcool e cigarro, parou com a maconha há seis meses); G., 17 anos (consome álcool e maconha); J., 17 anos (consome álcool e cigarro, parou com a maconha há seis meses e com o lança perfume há três anos) e N., 17 anos (consome álcool, cigarro e maconha, parou com a cocaína há um ano).

A estrutura familiar também é tida como fator de proteção ou risco. No caso dos/as adolescentes reincidentes, é percebido que ela se tornou um fator de risco. Verifica-se que 04/13 adolescentes reincidentes, 03/13 são filhos de pais separados e possuem histórico familiar comprometido com atos infracionais e criminais como: abandono do filho por parte da mãe (1), abandono do filho por parte do pai (1), pai está retido por tráfico (1); pai retido por tentativa de homicídio em bar (1); mãe usuária de crack (1), pai usuário de crack (1) e mãe se suicidou quando o filho ainda era criança (1).

Corrobora a importância do judiciário ao estabelecer uma medida socioeducativa ao/a adolescente, que seja compatível com seu ato infracional, considerando sua possibilidade de cumpri-la e seu histórico de vida.

Aos profissionais que atuam na medida de liberdade assistida, entende-se que precisam se apropriar da influência que possuem no processo de (re)socialização dos/as adolescentes em cumprimento da medida. Se o atendimento for bem estruturado, com foco na educação, (re)socialização e saúde, conduzido e elaborado de acordo com a real necessidade desse/a adolescente assistido/a poderá fazer total diferença no processo de auto-organização.

É fundamental o acompanhamento e (re)colocação desse/a adolescente na escola, garantindo seu direito de estudar e condições para que obtenha bom desempenho escolar, conforme estabelecido legalmente. Assim como, oportunidade para se preparar para o mercado de trabalho, ofertando cursos de capacitação profissional com títulos e horários que atendam ao público assistido e ao mercado de trabalho, e não apenas ocupá-los com atividades diversas. Visto que o trabalho proporciona transformações, autonomia e inserção social, como apontado por adolescentes que exerciam atividade remunerada, adquiriram confiança e respeito pela família, modificando seu grupo de amigos e lugares diferentes.

Assim, o/a adolescente poderá tornar-se sujeito autônomo, crítico e sabido dos seus direitos e deveres, com acesso à educação e saúde, sendo conduzido a (re)construir um projeto de vida. Caso contrário, esse/a adolescente poderá permanecer na criminalidade, sem expectativas e desconsiderando a importância da medida de liberdade assistida. Reproduz a visão errônea de simplesmente ir ao atendimento para assinar a carteirinha, esta que, segundo a coordenação técnica do CRAMI, 
Research, Society and Development, v. 10, n. 5, e9910514792, 2021

(CC BY 4.0) | ISSN 2525-3409 | DOI: http://dx.doi.org/10.33448/rsd-v10i5.14792

nem existe.

Cabe às famílias dos/as adolescentes assistidos/as e a toda a comunidade, participar e intervir nas tomadas de decisão políticas para que junto se possa integrar a proposta das medidas socioeducativas e cobrar dos poderes público e judiciário os direitos fundamentais para contribuir com o desenvolvimento físico, mental e moral em condições dignas para os/as adolescentes que cumprem medidas socioeducativas e, excepcionalmente, de sua família. Realizar articulações com toda rede social, com o propósito de dar continuidade e suporte ao trabalho realizado pela equipe técnica do CRAMI com os/as adolescentes e famílias assistidas em situação de vulnerabilidade.

Nos relatos dos/a depoentes podemos avaliar se a situação na qual se encontra o/a adolescente, ao final do processo de (re)socialização, favorece sua auto-organização, ou se a precariedade de sua situação inviabiliza a auto desorganização, reforçando vulnerabilidades, que favoreçam novos conflitos com a lei.

Esta pesquisa não esgota as possibilidades de se avançar nas discussões sobre as trajetórias singulares das vidas de adolescentes que entram em conflito com a lei e, ao refletirmos sobre as lacunas existentes, apontamos a urgência da realização de estudos que direcionem as lentes para a interseccionalidade presente no contexto situado da socioeducação.

\section{Referências}

Atlas do Desenvolvimento no Brasil. (2021). http://www.atlasbrasil.org.br/2020/pt/perfil_m/botucatu_sp>.

Anjos, S. N. R., \& Ramos, M. F. H. (2020). The schooling of adolescents in conflict with the law: a literature review. Research, Society and Development, 9(11), e62591110310. https://doi.org/10.33448/rsd-v9i11.10310

Barbiéri, L. F. (2019) Monitor da Violência. CNJ registra pelo menos 812 mil presos no país, 41,5\% não têm condenação. https://g1.globo.com/politica/noticia/2019/07/17/cnj-registra-pelo-menos-812-mil-presos-no-pais-415percent-nao-tem-condenacao.ghtml

Bardin, L. (1977). Análise de Conteúdo. Livraria Martins Fontes, 103-104.

Barone, R. E. M., \& Silva, A. M. (2015). Adolescente em cumprimento de Medida Socioeducativa, Capacitação para o trabalho e inserção no mundo do trabalho: desafios no contexto de Unidades de Privação de Liberdade. Rev. Fac. Educ. (Universidade do Estado de Mato Grosso), 24(2), 155-176.

Brasil (1990). Estatuto da Criança e do Adolescente, Lei n. ${ }^{\circ} 8.069$.

Brasil (2006). Sistema Nacional De Atendimento Socioeducativo - SINASE / Secretaria Especial dos Direitos Humanos - Brasília-DF: CONANDA.

Brasil (2012) Sistema Nacional de Atendimento Socioeducativo - Lei n ${ }^{\circ}$ 12.594, de 18 de janeiro de 2012. < http://www.planalto.gov.br/ccivil_03/_ato20112014/2012/lei/112594.htm>.

Brasil (2017). Levantamento Anual Sinase. Ministério dos Direitos Humanos.

Campos, R. G. (2017). Auto-organização na construção de projeto de vida pelo adolescente em ressocialização. 99 fls. Dissertação (Mestrado em Saúde Coletiva). Universidade Estadual Paulista.

Carrano, P. (2015). Educação de Jovens e Adultos e Juventude: o desafio de compreender os sentidos da presença dos jovens na escola da "segunda chance". <http://forumeja.org.br/go/files/Educa\%C3\%A7\%C3\%A3o\%20de\%20Jovens\%20e\%20Adultos\%20e\%20Juventude\%20-\%20Carrano.pdf >.

Coelho, B. I., \& Rosa, E. M. (2013). Ato Infracional e Medida Socioeducativa: Representações de Adolescentes em L.A. Psicologia \& Sociedade, 25(1): 163173 p.

Colombarolli et al (2014). Proposta de redução da idade penal: visão dos profissionais da psicologia. Psicol. Argum. 32(77), 19-26.

Conceição, W. L. da (2017). Histórias de vidas que se unem: a professora, o professor e os [elos com os] jovens infratores. 2017.136 fls. Tese (Doutorado em Educação) - Campinas: Universidade Estadual de Campinas, 2017. http://www.repositorio.unicamp.br/handle/REPOSIP/322308.

Conceição, W. L. da (2020). Histórias de vidas de professores/as e o fazer docente na socioeducação. Revista Prática Docente, 5(2), 1395-1409. https://doi.org/10.23926/RPD.2526-2149.2020.v5.n2.p1395-1409.id790

Conceição, W. L., Teixeira, J. D., \& Campos, R. G. (2020). Socioeducação. Olhares: Revista do Departamento de Educação da Unifesp, 8(2), 102-121. https://periodicos.unifesp.br/index.php/olhares/article/view/10625.

Costa et al (2011). Adolescente em conflito com a lei: o relatório psicossocial como ferramenta para promoção do desenvolvimento. Psicologia em Estudo, 16(3), 379-38. 
Research, Society and Development, v. 10, n. 5, e9910514792, 2021

(CC BY 4.0) | ISSN 2525-3409 | DOI: http://dx.doi.org/10.33448/rsd-v10i5.14792

Dubet, F. (2003). A escola e a exclusão. Cadernos de Pesquisa, (19), 29-45.

Ferreira, M. S. C., \& Pereira, M. A. O. (2012). O Cuidado em Saúde Mental: a escuta de pacientes egressos de um Hospital Dia. Rev. bras. enf., 65(2).

Jacobina, O. M. P., \& Costa, L. F. (2007). Cadernos de Psicologia Social do Trabalho, 10(2), 95-110.

Lane, S. T. M. (1997). Consciência/alienação: a ideologia no nível individual. In: Lane, S. T. M., Godo, W. (org.). Psicologia Social. (13a ed.), Editora Tatuapé, p. 40-47.

Lussi, I. A., Freitas, H., \& Pereira Jr., A (2006). Proposta de um Instrumento de Autoavaliação em saúde mental. Cadernos de Terapia Ocupacional da UFSCar $12,5-14$.

Medeiros, F. C., \& Paiva, I. L. (2015). A convivência familiar no processo socioeducativo de adolescentes em privação de liberdade. Estudos e Pesquisas em Psicologia, 15(2), 568-586 Universidade do Estado do Rio de Janeiro Rio de Janeiro, Brasil.

Minayo, M. C. S. (2004). O desafio do conhecimento: pesquisa qualitativa em saúde. (8a ed.), Hucitec.

Müller, K. de A., Oliveira, U. P. de, \& Conceição, W. L. da. (2021). Ensino da educação física entre muros e grades: narrativas (auto)biográficas e reflexões compartilhadas. Cenas Educacionais, 4, e10773. https://revistas.uneb.br/index.php/cenaseducacionais/article/view/10773

Neto, C. (2010). Da prática do desvio ao protagonismo. Psico, PUCRS, 41(1), 128-136.

Oliveira Netto, de O. (2008). Reabilitação social e escolaridade: um estudo sobre a relação da escola e as medidas socioeducativas de liberdade assistida (LA) e prestação de serviços à comunidade (PSC). Mestrado. (Educação: História, Política e Sociedade). Pontifícia Universidade Católica de São Paulo.

Oliveira, U. P., et al (2021). Adolescentes e conduta infracional: espaços, equipamentos e conteúdos de esporte e lazer. Movimento (ESEFID/UFRGS), e26079, <https://seer.ufrgs.br/Movimento/article/view/102733>.

Oliveira, U. P. de, Conceição, W. L., Oliveira, R. A. C., Grunnenvaldt, J. T., \& Reverdito, R. S. (2020). O Esporte e o Lazer em Contextos de Medidas Socioeducativas no Brasil: Panorama e Análise da Produção Científica. LICERE - Revista Do Programa De Pós-graduação Interdisciplinar Em Estudos Do Lazer, 23(4), 249-277. https://doi.org/10.35699/2447-6218.2020.26680

Oliveira, U., Conceição, W., Grunnenvaldt, J., Olivera, R., \& Reverdito, R. (2020). Esporte e lazer no plano individual de atendimento de adolescentes em cumprimento de medida socioeducativa de internação. Movimento (ESEFID/UFRGS), 26, e26054. https://doi.org/10.22456/1982-8918.101588

Passamani, R., \& Rosa, E. M. (2009). Conhecendo um Programa de Liberdade Assistida pela Percepção de seus Operadores. Psicologia Ciência e Profissão, 2009,29 (2), 330-345p.

Pereira Jr, A., \& Pereira, M. A. (2010). O. Teoria da Auto-Organização: uma Introdução e Possível Aplicação nas Ciências da Saúde. Simbio-Logias 3, p.102114.

Pereira Jr, A., Lussi, I. A. O., \& Pereira, M. A. O. (2002). O Universo da Mente humana e a Saúde Mental: uma síntese Multidisciplinar. Mente. In: Universos do Conhecimento. Martins, RP. p. 201-219. Faculdade de Ciências e Letras da UFMG Belo Horizonte.

Quinelatto Caparrós, R. F. (2013). Entre saberes, sabores e desafios da tarefa educativa com jovens em conflito com a lei: como as educadoras significam os processos educativos do espaço do programa de medidas socioeducativas em meio aberto. 2013. 174 fls. Dissertação (Mestrado em Educação). São Paulo: Universidade Federal de São Carlos.

Quinelatto, R. F. (2015). O programa de medidas socioeducativas em meio aberto: educação ou reprodução do aprendizado da rua? Tese, 235 fls. (Doutorado em Educação). São Paulo: Universidade Federal de São Carlos.

Scisleski, A. C. C., et al (2015). Medida socioeducativa de internação: estratégia punitiva ou protetiva? Psicologia e Sociedade, $505-515$.

Silva et al (2015). Adolescentes em conflito com a lei no Brasil: pesquisa para intervir. Mudanças - Psicologia da Saúde, 23 (1), 41 -48.

Silva, I. R. O., \& Salles, L. M. F. (2011). Estudos de Psicologia. 28(3). 353-362.

Silva, T. M. T. (2003). Mamãe a professora quer falar com você. Eu não fiz nada. In. Evangelista, F., Gomes, P. de T. (orgs). Educação para o pensar. Campinas: Alínea.

Teixeira, M. L. T. (2006). Evitar o desperdício de vidas. In Ilanud, Abmo, Sedh, Unfpa (Org.). Justiça Adolescente e ato infracional: socioeducação e responsabilização. (427-448p.). Ilanud. 